\title{
Malignancy in Systemic Lupus Erythematosus (SLE) Patients
}

\author{
Rizna Abdul Cader*, Amy Khoo Mei Yee, Azrul Yassin, Ismail Ahmad, \\ Siti Nurfatin Haron
}

\begin{abstract}
Background: Malignancies are among the leading causes of death in Systemic Lupus Erythematosus (SLE) patients with studies reporting a higher prevalence of malignancy in SLE patients compared to the general population. We wanted to determine the frequency of cancer in a cohort of SLE patients and identify its associated risk factors. Methods: Cross-sectional study involving SLE patients attending the nephrology outpatient clinic, Universiti Kebangsaan Malaysia Medical Centre between January and June 2014. Results: We recruited 228 patients (207 female, 21 male), aged $40.48 \pm 12.86$ years with mean SLE duration of $11.65 \pm 6.46$ years. Majority (87\%) had lupus nephritis and were in remission with a median SLEDAI score $2(0,14)$. Majority $(89 \%)$ were on corticosteroid with either a steroid sparing agent like mycophenolate mofetil (15.4\%), azathioprine (36.8\%) or ciclosporin (15.4\%). One hundred and sixty $(70.2 \%)$ patients were either receiving or had received intravenous cyclophosphamide with median dose of 5,173.6 $\pm 3,242.4 \mathrm{mg}$. Seven female patients were diagnosed with cancer during the course of their SLE with 56 (34-78) years being median age at malignancy and SLE duration of 4 (0-12) years. Majority (5/7) had lupus nephritis and all patients a median dose of prednisolone $10(2.5,10) \mathrm{mg}$ with $10(4-24)$ years of steroids. Two patients had a family history of cancer with majority developing cancer after the diagnosis of SLE. Two patients received intravenous cyclophosphamide prior to the development of cancer for their SLE compared to overall cohort of 160. Three patients had colorectal cancer, 2 had cervical cancer, 1 had breast cancer, and one patient had germ cell tumour and one thyroid cancer. All patients had their cancer successful treated with no signs of recurrence. Conclusion: We found a lower occurrence of cancer in our SLE patients as compared with the reported literature.
\end{abstract}

Keywords: Cancer- cyclophosphamide- lupus nephritis- malignancy- systemic lupus erythematosus

Asian Pac J Cancer Prev, 19 (12), 3551-3555

\section{Introduction}

Systemic lupus erythematosus (SLE) is one of the commonest autoimmune diseases affecting young and middle-aged females. Despite improved survival in SLE, morbidity related to the disease and its treatment remains considerable. Complications such as cardiovascular disease and cancer have become major causes of morbidity and mortality (Chaiamnuay et al., 2007; Skaggs et al., 2012). Malignancies are among the leading causes of death in SLE patients (Bernatsky et al., 2006). According to the World Health Organization, the prevalence of malignancy worldwide had been reported to be 43 cases per 100,000 individuals (Sultan et al., 2000). The association of SLE with malignancies is more common than the general population and its occurrence has been reported to be 3.2-11.4\% (Gayed et al., 2009; Bernatsky et al., 2012). SLE patients are more likely to be diagnosed with certain types of cancer as compared to the general population (Bernatsky et al., 2005; Parikh-Patel et al., 2008; Kiss et al., 2010). Haematological malignancies especially
non-Hodgkin's lymphoma are increased in SLE patients (Bjornadal et al., 2002; Liang et al., 2010; Bernatsky et al., 2013; Fallah et al., 2014). However, on the contrary, hormone-associated malignancies like breast cancer are decreased in SLE patients (Bernatsky et al., 2011).

The mechanism underlying the association between SLE and cancer remains largely unanswered. It is thought that the overstimulation of B-cells due to SLE, coupled with defects in the immune system's surveillance system increases the risk of cancer (Bernatsky et al., 2014). Other suggested pathways linking SLE and cancer include medication exposures, or even interactions between medications and viral exposures. The potential link between cancer risk and drug exposure in SLE remains difficult to establish definitively because of the close association between disease activity and immunosuppression (Bernatsky et al., 2008). Cumulative exposure to immunosuppressive drugs such as cyclophosphamide is another suggested risk factor for increasing cancer incidence in SLE patients compared to general population (Dreyer et al., 2011). 
Despite the accumulation of evidence of an association between SLE and cancer over the past few years, it is still controversial whether the risk of cancer is increased in SLE patients. Many previous studies suggested no significant difference whereas the two large multicentres, cohort studies reported SLE patients had an increased cancer risk compared to the general population (ParikhPatel et al., 2008; Bernatsky et al., 2013). We therefore embarked on this study to see the frequency and type of cancer in Malaysian SLE patients.

\section{Materials and Methods}

This was a cross-sectional study involving SLE patients attending the nephrology outpatient clinics at Universiti Kebangsaan Malaysia Medical Centre (UKMMC) between February and June 2014. This study was approved by the UKMMC Ethics and Research Committee (FF-2014-050). SLE patients are reviewed routinely every 3 to 4 months at our institution unless clinically indicated for earlier review. We included all SLE patients diagnosed according to the updated American College of Rheumatology classification criteria, aged 1870 years old with more than 3 months of follow-up at our instituition (Hochberg, 1997). We excluded patients who were unable to comprehend English or Malay. Patients with mixed connective tissue disorder, undifferentiated connective tissue disease and overlap syndrome were excluded.

We used a screening questionnaire to screen patients who were diagnosed with cancer. We collected demographic and laboratory data on all screened patients and their disease activity using the Systemic Lupus Erythematosus Disease Activity Index (SLEDAI) scored by a physician (Gladman et al., 2002). We also collected data on cancer risk factors, such as smoking, alcohol consumption and body mass index.

For those patients who responded to having cancer, we counterchecked their medical records and recorded diagnosis of cancer regardless of the method of diagnosis (e.g. screening program for cervical and breast cancer or after the onset of clinical features suggestive of malignancy). We gathered data on the type of cancer and histology, treatment received immunosuppressive regimen (dose and duration) and cancer outcomes. Cancers diagnosed before and after the diagnosis of SLE were included. We only looked at cancers that were confirmed histologically.

\section{Results}

We screened 254 patients and excluded 26 patients as they either couldn't comprehend the language or had mixed connective tissue disease. Therefore we recruited 228 patients (207 female, 21 male) and their demographics are shown on Table 1. Majority (89\%) were on corticosteroids with a corticosteroid sparing agent such as mycophenolate mofetil $(\mathrm{n}=35,15.4 \%)$, azathioprine $(\mathrm{n}=84,36.8 \%)$ or cyclosporine $\mathrm{A}(\mathrm{n}=35,15.4 \%)$. One hundred and sixty patients $(70.2 \%)$ were either receiving or had received intravenous cyclophosphamide with a mean dose of 5,173.6 $\pm 3,242.4 \mathrm{mg}$.

Of the 228 patients, 8 patients (all females) were diagnosed with cancer. However, one patient developed cancer 19 years before the diagnosis of SLE and was therefore excluded in the analysis. Of the remaining 7 patients (5 Malays and 2 Chinese), 6 were married and their median age at diagnosis of cancer was 56 (34-78) years with median SLE duration of $4(0-12)$ years at the time cancer diagnosis. Their median duration of follow up post cancer was $8(0-13)$ years. Majority $(5 / 7)$ had lupus nephritis with the remaining two having only musculoskeletal. All patients were on steroids with a median prednisolone dose of $10(2.5,10) \mathrm{mg}$ and median duration of 10 (4-24) years. Of these 7 patients, two patients were not on any immunosuppressive therapy at the time of cancer diagnosis, whereas the remaining five were on some immunosuppressive therapy as shown in Table 2. All 7 were in remission with median SLEDAI of 0 (0-4).

Majority were diagnosed with cancer within few years of SLE diagnosis. However, one patient was diagnosed with breast cancer one year before the diagnosis of SLE was made and another patient was diagnosed with colorectal cancer one and a half years before SLE diagnosis. The type

Table 1. Demographics of All SLE Patients

\begin{tabular}{|c|c|}
\hline Characteristics & $\begin{array}{c}\text { Number }(\%) / \text { Mean } \pm \text { SD } \\
n=228\end{array}$ \\
\hline Age (years) & $40.48 \pm 12.86$ \\
\hline \multicolumn{2}{|l|}{ Gender (n) } \\
\hline Male & $21(9.2)$ \\
\hline Female & $207(90.8)$ \\
\hline \multicolumn{2}{|l|}{ Race (n) } \\
\hline Malay & $112(49.1)$ \\
\hline Chinese & $102(44.7)$ \\
\hline Indian & $13(5.7)$ \\
\hline Others & $1(0.4)$ \\
\hline \multicolumn{2}{|l|}{ Organ involvement (n) } \\
\hline Lupus nephritis & $198(86.8)$ \\
\hline Musculoskeletal & $128(56.1)$ \\
\hline Haematological & $115(50.4)$ \\
\hline CNS lupus & $27(11.8)$ \\
\hline APLS & $23(10.1)$ \\
\hline SLEDAI score & $2(0,14)$ \\
\hline Duration of SLE (years) & $11.65 \pm 6.46$ \\
\hline Body mass index $\left(\mathrm{kg} / \mathrm{m}^{2}\right)$ & $25.09 \pm 5.50$ \\
\hline \multicolumn{2}{|l|}{ Laboratory data } \\
\hline Urea (mmol/L) & $5.19 \pm 3.42$ \\
\hline Creatinine (umol/L) & $91.19 \pm 62.15$ \\
\hline eGFR $(\mathrm{mls} / \mathrm{min}) / / 1.73 \mathrm{~m}^{2}$ & $75.54 \pm 27.6$ \\
\hline Albumin $(g / L)$ & $41.37 \pm 5.15$ \\
\hline $\operatorname{ESR}(\mathrm{mm} / \mathrm{hr})$ & $42.19 \pm 24.85$ \\
\hline Urine PCI (mg/mmol) & $0.05(0.01-0.67)$ \\
\hline
\end{tabular}

AIHA, Autoimmune Haemolytic Anaemia; CNS, Central Nervous System; APLS, Antiphospholipid Syndrome; SLEDAI, Systemic Lupus Erythematosus Disease Activity; eGFR, Estimated Gromerular Filtration Rate; ESR, Erythrocyte Sedimentation Rate 
Table 2. Types of Cancer and Treatment Received

\begin{tabular}{|c|c|c|c|c|c|c|}
\hline $\begin{array}{l}\text { Age/Gender } \\
\text { (years) }\end{array}$ & $\begin{array}{l}\text { Duration } \\
\text { of SLE } \\
\text { (years) }\end{array}$ & $\begin{array}{l}\text { Duration of } \\
\text { SLE at cancer } \\
\text { development } \\
\text { (years) }\end{array}$ & $\begin{array}{l}\text { Cyclopho } \\
\text { sphamide before } \\
\text { cancer and dose }\end{array}$ & $\begin{array}{l}\text { Immunosuppressive } \\
\text { regimen at cancer } \\
\text { diagnosis }\end{array}$ & Type of cancer & Outcome \\
\hline 36/female & 20 years & 11 years & Yes 6.8 grams & $\begin{array}{l}\text { Prednisolone } \\
\text { Cyclosporin and } \\
\text { Azathioprine }\end{array}$ & $\begin{array}{l}\text { Germ cell } \\
\text { tumour }\end{array}$ & $\begin{array}{l}\text { Surgery remission but } \\
\text { residual hemianopia }\end{array}$ \\
\hline 39/female & 14 years & 2 years & Yes 6 grams & $\begin{array}{c}\text { Prednisolone and } \\
\text { MMF }\end{array}$ & Cervical cancer & Surgery (remission) \\
\hline $55 /$ female & 7 years & $\begin{array}{l}\text { One year } \\
\text { before SLE was } \\
\text { diagnosed }\end{array}$ & No & None & Breast cancer & $\begin{array}{l}\text { Mastectomy } \\
\text { and Tamoxifen } \\
\text { (remission) }\end{array}$ \\
\hline $56 /$ female & 4 years & $\begin{array}{l}1.5 \text { years } \\
\text { before SLE was } \\
\text { diagnosed }\end{array}$ & No & None & $\begin{array}{l}\text { Colorectal } \\
\text { cancer }\end{array}$ & $\begin{array}{l}\text { Surgery, radiotherapy } \\
\text { and chemotherapy }\end{array}$ \\
\hline $66 /$ female & 24 years & 11 years & No & Prednisolone & Cervical cancer & $\begin{array}{l}\text { Surgery with total } \\
\text { hysterectomy }\end{array}$ \\
\hline $68 /$ female & 22 years & 12 years & No & Prednisolone & $\begin{array}{l}\text { Colorectal } \\
\text { Cancer }\end{array}$ & Awaiting surgery \\
\hline 78/female & 6 years & 4 years & No & $\begin{array}{l}\text { Prednisolone } \mathrm{d} \text { and } \\
\text { Azathioprine }\end{array}$ & $\begin{array}{c}\text { Colorectal } \\
\text { cancer with } \\
\text { liver metastases }\end{array}$ & $\begin{array}{l}\text { Surgery but not fit for } \\
\text { chemotherapy }\end{array}$ \\
\hline
\end{tabular}

MMF, Mycophenolate mofetil

of cancers and their immunosuppressive therapy is shown on Table 2. Two patients had a family history of cancer. Of these 7 patients, 4 patients had received intravenous cyclophosphamide with only 2 patients receiving it before they developed cancer. The other two patients received cyclophosphamide after their cancer was treated. Five patients presented with symptoms of cancer whereas the two patients with cervical cancer were picked up on routine screening. Of these 7 patients, 5 patients were screened for both breast and cervical cancer.

All patients had surgery for their cancer and their outcomes are tabulated on Table 2. Both patients with cervical cancer had surgery and as early stages didn't need any further treatment. The patient with germ cell tumour had resection but had residual hemianopia.

Of the 228 patients, a cervical smear was not indicated in 90 patients. However, of the 138 patients in whom a cervical smear was indicated, only 83/138 (60.1\%) had a cervical smear. Similarly, a mammogram was indicated in 99 patients but only 36/99 (36.4\%) had a mammogram.

On further analysis, we found no association between cyclophosphamide, mycophenolate mofetil or azathioprine with the development of cancer.

\section{Discussion}

It has been thought that SLE activity and stimulation of the immune system predisposes the risk of cancer (Bernatsky et al., 2008; Bernatsky et al., 2014). Another school of thought has been that the SLE treatment causes the cancer (Dreyer et al., 2011). Other risk factors that may increase cancer risk in SLE patients include genetic predisposition and lifestyle-related risk factors (Kiss et al., 2010; Goobie et al., 2015). There is controversial data on duration of SLE and development of cancer. Some studies have shown long disease duration to be associated with cancer (Kang et al., 2010). Whereas, others have shown that malignancy develops within the first two years of SLE diagnosis (Bjornadal et al., 2002; Bernatsky et al., 2005). Our study showed that it varied and we had patients presenting with cancer one year even before diagnosis of SLE, although the majority developed cancer more than two years of SLE diagnosis and in keeping with Hildalgo-Conde et al (2013). The occurrence of cancer was $3.07 \%$ in our cohort and much lower than the reported literature (Gayed et al., 2009; Bernatsky et al., 2012).

Cancer has been associated with SLE disease activity but we did not find that as most patients were in remission. Although majority were on low dose immunosuppression at the time of cancer diagnosis, they had a cumulative effect of the immunosuppressive therapy as they had been on SLE treatment for some time. Our group of patients were older than most of the described literature and it could be that they were the right age group for developing cancer like the general population and in keeping with a Spanish study (Hildalgo-Conde et al., 2013). Furthermore, to strengthen this argument is the type of cancer our patients developed were not haematological as commonly reported in the literature but rather cancers seen in the general population (Bjornadal et al., 2002; Bernatsky et al., 2011). We also found that types of cancers in our SLE patients were in keeping with the Malaysian national cancer registry report whereby breast cancer and colorectal cancers were the leading cancers (www.nci.moh.gov.my). On further review of the Malaysian cancer registry, the three commonest cancers in females were breast (32.1\%), followed by colorectal $(10.7 \%)$ and cervical $(7.7 \%)$ cancer. Although many authors have reported increased risk of haematological malignancies in SLE patients' we did not find this and we believe this may be because our patients 
developed cancers common for their age (Zintzaras et al., 2005; Chen et al., 2010; Liang et al., 2010; Bernatsky et al., 2013; Fallah et al., 2014;).

One study showed that haematological involvement in SLE was associated with increased risk of cancer occurrence but we did not find this despite a nearly half of our SLE patients having haematological involvement.

Whether patients with SLE are at the greater risk of cancer after exposure of immunosuppressive agents remains controversial. On further analysis of the association between cyclophosphamide, mycophenolate mofetil and azathioprine with cancer, we found no association and in keeping with some of the reported literature (Hildalgo-Conde et al., 2013; Dey et al., 2015). Others have demonstrated the association although mainly restricted to cyclophosphamide and cancer (Kang et al., 2010; Dreyer et al., 2011; Bernatsky et al., 2014; Goobie et al., 2015). The effects of cyclophosphamide may be direct, through immunosuppression and cytotoxicity, or indirect by promoting emergence of oncogenic viruses like Epstein - Barr virus and Human Papilloma Virus (Goobie et al., 2015). Cyclophosphamide therapy, especially with cumulative dose more than 6 grams was associated with an increased risk of cancer in one study (Kang et al., 2010). However, even though 160 patients in our cohort were treated with cyclophosphamide, only 2 patients developed cancer after receiving cyclophosphamide and even these were not the cyclophosphamide associated cancers associated with such as bladder or haematological. These two patients had received more than 6 grams of cyclophosphamide and one patient developed germ cell tumour whereas the other one developed cervical cancer. We had no cases of bladder cancer despite a high prescription of cyclophosphamide.

Authors have reported an increase incidence of cervical dysplasia and cancer in SLE with one paper reporting up to $16 \%$ of patients who received cyclophosphamide having an abnormal cervico-vaginal cytology (Cibere et al., 2001; Ognenovski et al., 2004; Parikh-Patel et al., 2008; Goobie et al., 2015). It is thought this may be due to decreased clearance of the human papilloma virus, which is an innate characteristic of SLE patients or could be a 'cyclophosphamide effect'. Cervical cancer accounted for $28.6 \%$ of our cancers. In our study we found the screening uptake for both cervical smear and mammogram was low and there may be an underreporting of cervical cancers in our study. Despite counselling, we found that cervical cancer screening was low in our cohort and in keeping with Bernatsky et al (2006) who reported that that SLE patients undergo cancer screening even less frequently than the general population. Studies have recommended that SLE patients should undergo screening for cancer just like the general population (Tessier-Cloutier B et al., 2015).

There is very little literature on the association of SLE and skin cancers. One meta- analysis reported a lower incidence of melanoma in SLE patients (Cao et al., 2015) whereas Singh et al., 2016 found no increased incidence albeit only in cutaneous SLE population. We did not find any cases of skin cancer and not sure whether their risk is reduced through a protective effect of SLE or because of the inherent nature of SLE patients to avoid sun and use SPF or whether it has something to do with the genetics of Asian skin and melanin.

Our study has some limitations in that the subjects were patients selected from a single center and the total number of cancer was small.

In conclusion, we found the occurrence of cancer in SLE patients was 3\% and lower than the reported literature. Our patients had mainly cancers related to the general population, except for the cervical cancer. We also noted that there was poor uptake of cancer screening recommendations and need to implement more stringent measures so that cancers could be detected early in this group of high risk patients.

\section{Ethical Responsibility}

We would like to thank the Dean of Universiti Kebangsaan Malaysia for giving us a grant to do the above study (FF-2014-050) and for allowing us to publish this data.

\section{Conflict of interest}

All authors declare no conflict of interest

\section{Acknowledgements}

We would like to thank the Dean of Universiti Kebangsaan Malaysia for allowing us to publish this data.

\section{References}

Bernatsky S, Boivin JF, Joseph L, et al (2005). An international cohort study of cancer in systemic lupus erythematosus. Arthritis Rheum, 52, 1481-90

Bernatsky S, Boivin J, Manzi S, et al (2006). Mortality in systemic lupus erythematosus. Arthritis Rheum, 54, 2550-57.

Bernatsky SR, Cooper GS, Mill C, et al (2006). Cancer screening in patients with systemic lupus erythematosus. J Rheumatol, 33, 45-9.

Bernatsky S, Ramsey-Goldman R, Clarke A (2006). Malignancy and autoimmunity. Curr Opin Rheumatol, 18, 129-34.

Bernatsky S, Boivin JF, Joseph L, et al (2008). The relationship between cancer and medication exposures in systemic lupus erythematosus: a case-cohort study. Ann Rheum Dis, 67, 74-9.

Bernatsky S, Ramsey-Goldman R, Foulkes W, Gordon C, Clarke A (2011). Breast, ovarian, and endometrial malignancies in systemic lupus erythematosus: A meta-analysis. Br J Cancer, 104, 1478-81.

Bernatsky S, Kale M, Ramsey-Goldman R, Gordon C, Clarke AE (2012). Systemic lupus and malignancies. Curr Opin Rheumatol, 24, 177-81.

Bernatsky S, Ramsay-Goldman R, Labrecque J, et al (2013). Cancer risk in systemic lupus: an updated international multi-centre cohort study. J Autoimmun, 42, 130-5

Bernatsky S, Ramsey-Goldman R, Joseph L, et al (2014). Lymphoma risk in systemic lupus: effects of disease activity versus treatment. Ann Rheum Dis, 73, 138-42.

Bjornadal L, Lofstrom B, Yin L, Lundberg IE, Ekbom A (2002). Increased cancer incidence in a Swedish cohort of patients with systemic lupus erythematosus. Scand J Rheum, 31, 66-71. 
Cao L, Tong H, Xu G, et al (2015). Systemic lupus erythematous and malignancy risk: a meta-analysis. PLoS One, 10, e0122964.

Chaiamnuay S, Bertoli AM, Roseman JM, et al (2007). African-American and Hispanic ethnicities, renal involvement and obesity predispose to hypertension in systemic lupus erythematosus: results from LUMINA, a multi-ethnic cohort (LUMINAXLV). Ann Rheum Dis, 66, 618-22.

Chen YJ, Chang YT, Wang CB, et al (2010). Malignancy in Systemic Lupus Erythematosus: a nation-wide cohort study in Taiwan. Am J Med, 123, 1150-6.

Cibere J, Sibley J, Haga M (2001). Systemic lupus erythematosus and the risk of malignancy. Lupus, 10, 394-400.

Dey D, Kenu E, Isenberg DA (2013). Cancer complicating systemic lupus erythematosus - a dichotomy emerging from a nested case-control study. Lupus, 22, 919-27.

Dreyer L, Faurschou M, Mogensen M, Jacobsen S (2011). High incidence of potentially virus-induced malignancies in systemic lupus erythematosus: a long-term follow-up study in a Danish cohort. Arthritis Rheum, 63, 3032-7.

Fallah M, Liu X, Ji J, et al (2014). Autoimmune diseases associated with non-Hodgkin lymphoma: a nationwide cohort study. Ann Oncol, 25, 2025-30.

Gayed M, Bernatsky S, Ramsey-Goldman R, et al (2009). Lupus and cancer. Lupus, 18, 479-85.

Gladman DD, Ibanez D, Urowitz MB (2002). Systemic lupus erythematosus disease activity index 2000. J Rheumatol, 29, 288-91.

Goobie GC, Bernatsky S, Ramsey-Goldman R, Clarke AE (2015). Malignancies in systemic lupus erythematosus - a 2015 update. Curr Opin Rheumatol, 27, 454-60.

Hildalgo-Conde A, Liger MH, Abarca-Costalago M, et al (2013). Incidence of cancer in a cohort of Spanish patients with systemic lupus erythematosus. Rheumatología Clínica, 9, 359-64.

Hochberg MC (1997). Updating the American College of Rheumatology revised criteria for the classification of systemic lupus erythematosus. Arthritis Rheum, 40, 1725.

Kang KY, Kim HO, Yoon HS, et al (2010). Incidence of cancer among female patients with systemic lupus erythematosus in Korea. Clin Rheumatol, 29, 381-8.

Kiss E, Kovacs L, Szodoray P (2010). Malignancies in systemic lupus erythematosus. Autoimmun Rev, 9, 195-9.

Liang J, Sun LM, Yeah JJ, et al (2012). Malignancies associated with systemic lupus erythematosus in Taiwan: a nationwide population-based cohort study. Rheumatol Int, 32, 773-8.

Ognenovski VM, Marder W, Somers EC, et al (2004). Increased incidence of cervical intraepithelial neoplasia in women with systemic lupus erythematosus treated with intravenous cyclophosphamide. J Rheumatol, 31, 1763-7.

Parikh-Patel A, White RH, Allen M, Cress R (2008). Cancer risk in a cohort of patients with systemic lupus erythematosus (SLE) in California. Cancer Causes Control, 19, 887-94.

Singh AG, Crowson CS, Singh S, et al (2016). Cancer risk in cutaneous lupus erythematosus: a population-based cohort study. Rheumatology (Oxford), 55, 2009-13.

Skaggs BJ, Hahn BH, McMahon M (2012). Accelerated atherosclerosis inpatients with SLE-mechanisms and management. Nat Rev Rheumatol, 8, 214-23.

Sultan SM, Ioannou Y, Isenberg DA (2000). Is there an association of malignancy with systemic lupus erythematosus? An analysis of 276 patients under long-term review. Rheum, 39, 1147-52.

Tessier-Cloutier B, Clarke AE, Pineau CA, et al (2015). What investigations are needed to optimally monitor for malignancies in SLE?. Lupus, 1, 1-7.
The Malaysian National Cancer Registry Report (MNCR) (2007-2011). www.nci.moh.gov.my.

Zintzaras E, Voulgarelis M, Moutsopoulos HM (2005). The risk of lymphoma development in autoimmune diseases: a meta-analysis. Arch Intern Med, 165, 2337-44.

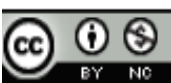

This work is licensed under a Creative Commons AttributionNon Commercial 4.0 International License. 